\title{
EXPERIENCES WITH FROG BREATHING TETRAPLEGIC POLIO VICTIMS AS TELEPHONE OPERATORS
}

\author{
By G. M. Pool, M.D. and G. J. v. Weerden, M.D. \\ The Rehabilitation Department and the Respiratory Unit of the \\ Zuiderziekenhuis, Rotterdam (Holland)
}

\section{INTRODUCTION}

Tetraplegic polio victims have different problems concerning their paralysed muscles than most patients with cord damage in the cervical and thoracic region of other aetiology. Sharrard (1956) found by counting the number of motor nerve cells, that with any amount above 40 per cent. a muscle will act with power, clinically indistinguishable from normal, and that with as few as two per cent of nerve motor cells, a muscle will show a detectable contraction. It may be assumed that with a severe paralysed polio patient needing constant artificial respiration, the motor cells in the anterior horn of both types, alpha and gamma are destroyed or badly damaged. For that reason it is impossible for the patient to react to a stimulus with his muscles.

The damage to the anterior horn of a tetraplegic polio patient in the case of severe paralysis, means also, absence or imbalance of the postural reflexes, which often leads to extreme scoliosis. This is in contrast with patients having a cervical cord lesion of traumatic origin, as observed by Guttmann and Silver (I965).

Since the polio epidemics of 1955 and 1957 the problem of artificial ventilation has been overcome by mechanical ventilatory aids. As the alpha and gamma cells are destroyed, passive movements of the thoracic paralysed region are not hindered by involuntary reflex actions, and it seems possible to go on with the artificial ventilation for many years; the sensory qualities not being disturbed.

All these things have been learnt from neuro-physiological research but were practically unknown, when Holland was struck by several, severe polio epidemics.

Forty-five patients with severe paralysis, including ventilatory paralysis were admitted to the respiratory unit of the Zuiderziekenhuis for longstanding artificial ventilation and general treatment.

Four patients died; two in the acute phase and the others, seven and I 3 years after the onset of their disease.

Twenty-six out of the $4 \mathrm{I}$ surviving patients improved to such an extent, that they could be discharged from hospital and enjoy an almost normal family and social life.

Fifteen tetraplegic patients never regained spontaneous ventilation sufficiently to enable them to do completely without artificial ventilation.

After careful psychological preparation a so-called home-care programme was instituted for five subjects, all married adults. These patients now live at home. Their relatives and friends were theoretically and practically trained in the management of the machines and in the diagnosing and treatment of all mishaps that could arise while performing artificial ventilation and nursing.

Ten tetraplegic children could not return home for several reasons, one being that they needed too much care (fig. I). Gradually they became somewhat 
independent. When they had sufficiently mastered the frog breathing technique an education programme was started.

Frog breathing, or rather as it should be called, glossopharyngeal breathing not only makes the patients free from their ventilator during the greater part of the day, by increasing their vital capacity considerably, but also provides a fairly effective immitation of the coughing mechanism, making them less dependent.

In the hospital garden, with the help of the Princess Beatrix Polio Fund and other organisations a specially designed bungalow was built called 'De Ark'. In this bungalow every individual has his own room and there is a 24 -hour service maintained by 12 helpers. During the night and after midday, the inhabitants

age distribution frogbreathing tetraplegic poliovictims (1973)

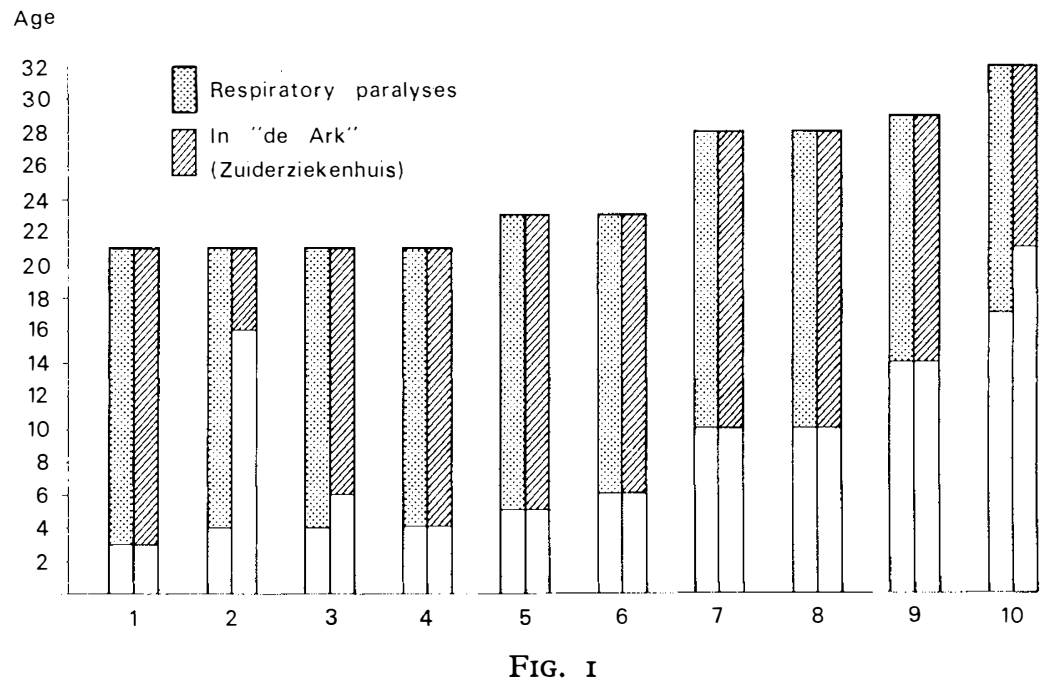

Three of the Ark inhabitants (2, 3, and 10) were sent in from other regions.

are connected to a poliomat respirator for the necessary supply of oxygen. The rest of the day they ventilate sufficiently by themselves.

Should Tetraplegic Frog Breathing Polio Victims Work? In I965 a report was brought out by a psychologist on questions arising from puberty of the inhabitants, although at that time several of them had already passed that period. On the whole the report encountered much resistance because it was thought the psychologist did not recognise enough the problem of the necessary 'patientcare'. He advised, for instance, work in a sheltered workshop. It was thought that the inhabitants were too handicapped and needed too much care for the usual work in a sheltered workshop. This was confirmed by the local authorities. The report however did provide a good stimulus to re-evaluate the problem of further education as a group.

Interviews with the inhabitants disclosed that they thought the typewriting work they were already doing rather boring. They often did not understand what they were typing. They wished to be employed in the hospital, although 
they did not know what at. Something had to be done to keep the group quiet and alert.

Work as a Telephone Operator. It was probably by chance that it was discovered that there might be a possibility for work as a telephone operator of a small department, to distribute the incoming and outgoing calls. With the help and advice of the experts of the P.T.T. a special telephone was constructed, making it possible to utilise the normal apparatus by pressing knobs instead of turning the dial, a movement most of the inhabitants cannot manage.

The adapted telephone was not the only problem to be solved. Much more difficult seemed the problem of having frog breathing polio victims speaking loudly, clearly and long enough for work as a telephone operator. For this problem, advice and help was obtained from the speech therapist of the telephone board. It was her job to examine and train the new operators. She told us that everybody who could speak loudly and clearly enough to be understandable, were able to communicate by telephone. She not only advised us, but also undertook the task of training and instructing our frog breathing tetraplegic 'telephone operators'.

In lessons of one hour a week, lasting one year, the speech therapist succeeded in improving the breathing and speech ability of the patients. And, what was probably most important, the rhythm of their speech was dramatically improved.

So since September 1969 in Zuiderziekenhui, there have been two telephone posts, one being in the rehabilitation department with a frog breathing telephone operator (figs. 2,3). They receive the normal salary for disabled workers on a six hour work basis, that is two hours as telephone operator and four hours for typewriting work.

\section{DISCUSSION}

In our opinion the work which the frog breathing telephone operators are doing is satisfying both for them and for all the other workers of the department, including most of the patients! The only assistance they need on the spot is undoing their raincoats!

They arrive at their post on schedule with their electric wheelchairs. Their absenteeism is very low indeed. Apart from the work performance, our telephone operators have a distinct influence on the other workers of the department and also on the patients. They can communicate with both of them by way of an intercom system and the patients can see their performance.

But what is it that makes the work of our new employees so gratifying? Is it just recreation? Of course, they are handicapped in fulfilling practically all labour that needs muscle power, but in the adapted function as an operator, they do not seem to be invalids so much. At least, they do not seem to be handicapped in their ability to meet other people, and in that way they do play an important role in the hospital community. To react and meet other people is one of the most essential things of daily life. We do meet each other by means of our eyes, our faces, our posture, our voices, but also with our skin, for instance by handshake.

Physiologically we meet each other especially by means of the organs which lie nearest the brain and are therefore suitable for a quick reaction. The only possibilities that remain to our frog breathing telephone operators to meet other people are their eyes, their faces and their voices. Thanks to the trick movements 


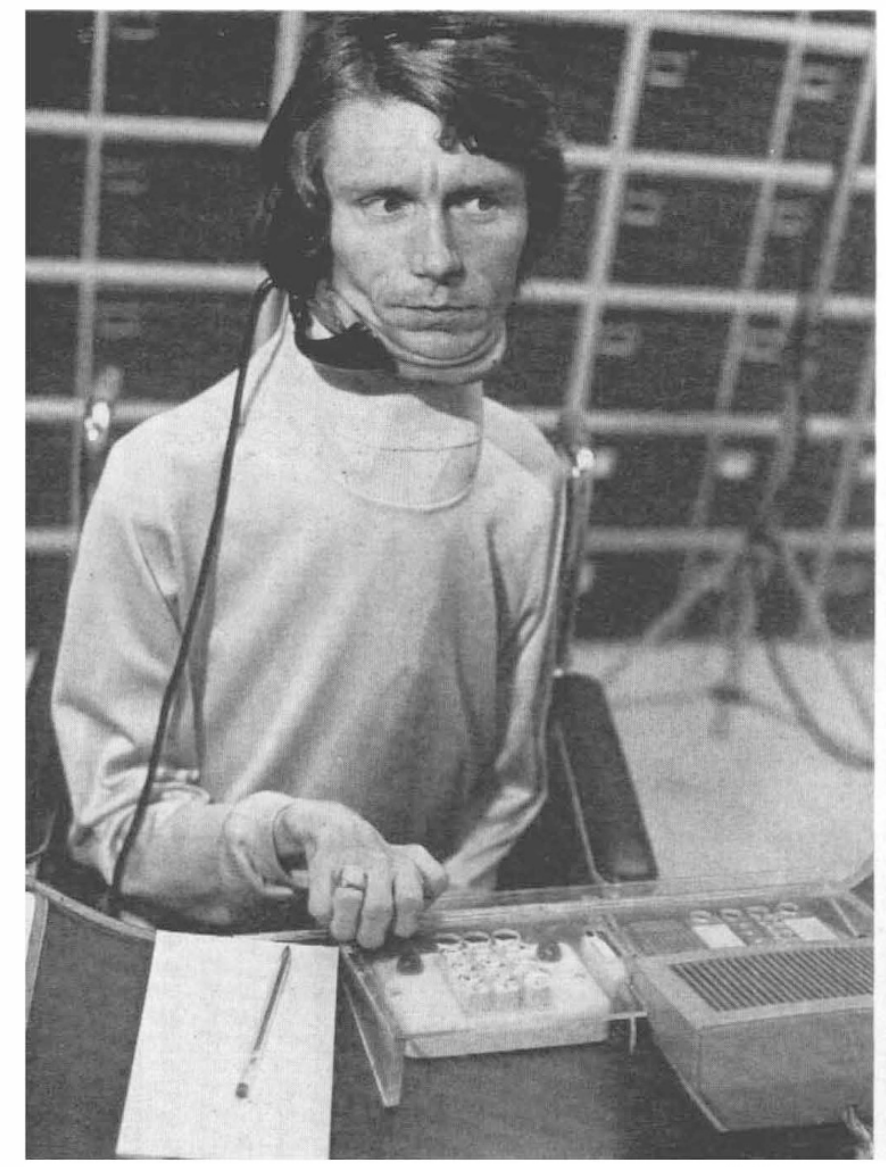

FIG. 2

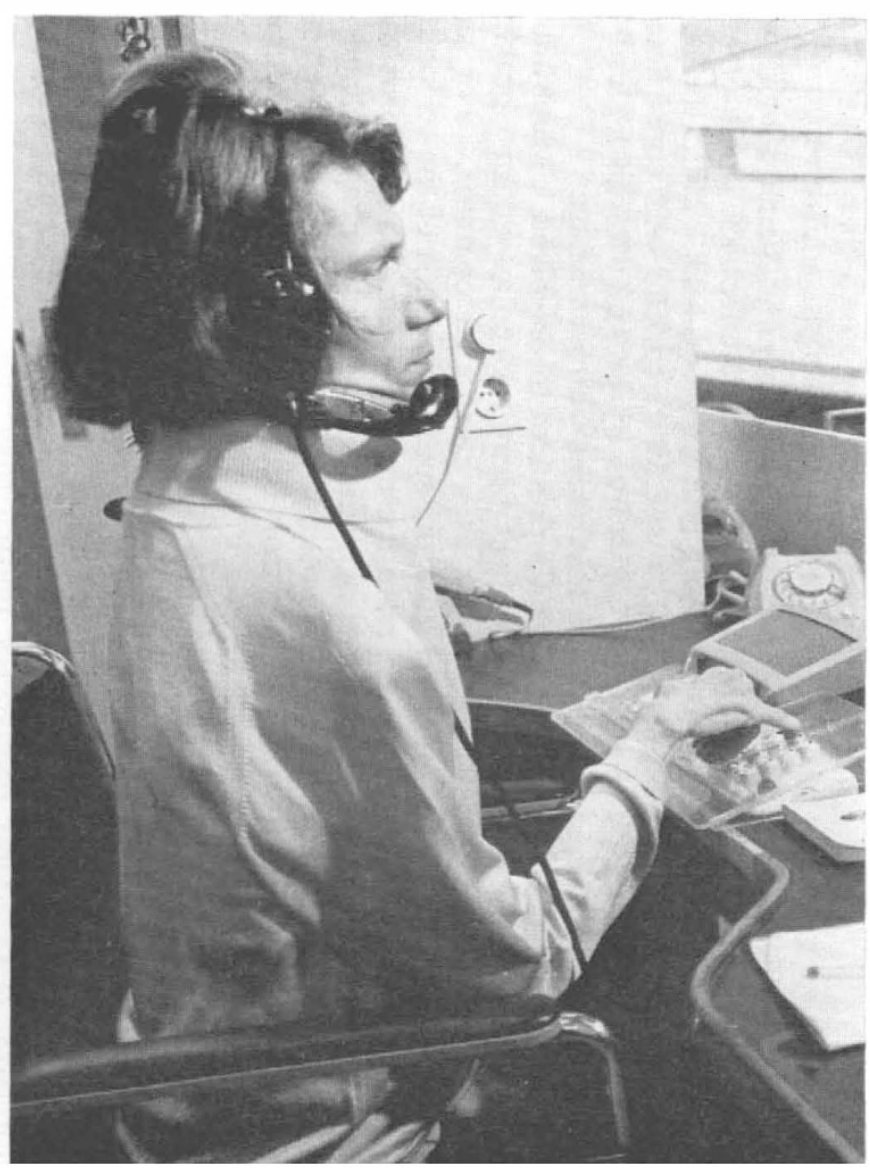

FIG. 3

Figs. 2 and 3. A frog breathing telephone operator with his adapted telephone. 
of their hands they can push the knobs of the adapted telephone and the intercom system. Due to the hand-eye interplay they can react to electrical signs to communicate with their voices with anyone who needs their help. So they can play a role and fulfil a task in the community they grew up in.

The Russian physiologist Bernstein stated that tone is not a condition of elasticity but a condition of readiness. Also he says that tone is not merely a condition of the muscles but of the entire neuromuscular apparatus (Pool, I97I). Although the neuromuscular apparatus of our frog breathing polio victims is badly damaged in the anterior horn we may assume that the work as a telephone operator fulfils the statement of Bernstein, concerning the readiness for what is left to them to react with. Basically it is the same principle initiated by Sir Ludwig Guttmann when he started the Games and Sport for Handicapped People, which is meeting and reacting to people in a group.

\section{SUMMARY}

Some details and thoughts are given about a group of Io tetraplegic frog breathing polio victims living next to a hospital and the role they play in the hospital community.

Their weak hands are not reflexly disturbed and they have a normal, functioning brain.

Our experiences might be also of value to other tetraplegics.

\section{REFERENCES}

Bernstein, N. (1967). The Coordination and Regulation of Movements. Oxford: Pergamon Press.

Guttmann, L. \& Silver, J. R. (1965). International fournal of Paraplegia, 3, I.

SHARRARD, W. J. W. (I956). Re-education in Walking after Poliomyelitis. IVe Symposium Bologna P I08 (1957) Brussels.

Pool, G. M. (I97I). International fournal of Paraplegia, 9, 7I.

\section{Discussion}

Dr. D. J. E. Cheshire (U.S.A.). We appreciate that glossopharyngeal breathing does have an enormous place in the polio patient. I have tried to increase the pharyngeal efficiency of spinal cord injured patients, the high tetraplegic, with total lack of success. I would be interested if any colleague, Dr. Pool or others, would tell me whether this is a different animal or whether it is merely my own inefficiency.

Chairman. Before the speaker is called upon to answer the question, is there any colleague who would wish to volunteer to answer this question.

SiR Ludwig GutTManN (G.B.). I think there is a difference between very high polios and high traumatic cervical lesions. The high traumatic cervical lesions of $\mathrm{C}_{3}$ and $\mathrm{C}_{4}$ have still auxilliary respiratory muscles, such as trapezius, sternomastoid and platysma, and they can be so mobilised that there is no need for frog breathing. I think frog breathing is really the last resort and it is important that this method of breathing is taught to physiotherapists. I think Dr. Pool's paper was a very important one in that it reminded us that there are certain cases where this kind of breathing is most essential. There is one point which perhaps has not been noticed. In the subjects shown with frog breathing the nostrils are very wide. This is the result of the overaction of the ali nasi muscles. This is the last resort these patients have for air entry through inspiration.

DR. Pool. (Netherlands). Thank you Dr. Cheshire for your question. I think it is just the polio patient who can manage frog breathing and, for quite a long time. 